Volume 10, No.3, May - June 2021

International Journal of Advanced Trends in Computer Science and Engineering

Available Online at http://www.warse.org/IJATCSE/static/pdf/file/ijatcse621032021.pdf

https://doi.org/10.30534/ijatcse/2021/621032021

\title{
On Topological Indices of Dual Graph of Benzene Ring Embedded in P-Type Surface in 2D Network
}

\author{
Azhar Iqbal ${ }^{1}$, Gohar Ali ${ }^{2}$, Javed Khan ${ }^{3}$, Gul Rahmat ${ }^{4}$, Muhammad Numan ${ }^{5}$, Andleeb Kausar \\ ${ }^{1}$ Department of Basic Sciences. Dawood University of Engineering and Technology, MA Jinnah road, Karachi, \\ Pakistan.azhar.iqbal@duet.edu.pk \\ ${ }^{2,4}$ Department of Mathematics, Islamia College Peshawar, Peshawar, Khyber Pakthunkhwa, Pakistan. \\ gohar.ali@icp.edu.pk, gulassms@gmail.com \\ ${ }^{3}$ Department of Mathematical Sciences. Federal Urdu University of Arts, Science and Technology, Gulshan \\ Iqbal, Karachi, Pakistan. javid.khan@fuuast.edu.pk \\ ${ }^{5,6}$ Department of Mathematics, COMSATS University Islamabad, Attock, Pakistan. \\ numantng@gmail.com, andleebmalik63@gmail.com \\ Corresponding Author: azhar.iqbal@duet.edu.pk
}

\begin{abstract}
The structure of any finite molecular graph which represent numerical quantities are known as topological indices. The importance of topological indices is generally linked with QSAR/QSPR. In this paper, we compute general Zagreb $\left(\mathrm{M}_{\alpha_{-}}\right)$index, general Randic connectivity $\left(\mathrm{R}_{\alpha-}\right)$ index, general sum-connectivity $\left(\chi_{\alpha}\right)$ index, atom-bond connectivity ( $\mathrm{ABC}$ ) index, and geometric-arithmetic (GA) index, $\mathrm{ABC}_{4}, \mathrm{GA}_{5}$, multiple Zagreb indices and Zagreb polynomial indices of the of dual graph of benzene ring embedded in P-type-surface in 2D network.
\end{abstract}

Key words: Topological Indices, Multiple Zagreb Indices, Zagreb Polynomials, Benzene Ring.

\section{INTRODUCTION AND DEFINITIONS}

In this paper all graphs are finite, simple and undirected. Let $V(G)$ and $E(G)$ be the vertex set and edge set of a graph. We follow the basic notation and terminologies of graph theory as in [1]. The vertices $u, v \in V(G)$ are adjacent (or neighbors) if $u$ and $v$ are end points of e $\epsilon E(G)$ and is incident with the vertices of $u$ and $v$ and $e$ is said to be connect $u$ and $v$. The set of all neighbors of a vertex $u$ of $\mathrm{G}$ denoted by $\mathrm{N}(\mathrm{u})$, is called the neighborhood of $\mathrm{v}$. The degree of a vertex is an undirected simple graph is the number of edges incident with it. The degree of the vertex $u$ is denoted by $d_{u}$ and $S_{u}$ is the sum of degrees of all vertices adjacent to the vertex $u$. In other words

$$
S_{u}=\sum_{v \in N(u)} d_{v},
$$

Where $\quad N(u)=\{v \in V(G): u v \in E(G)\}$

The application of molecular structure descriptors in nowadays a standard procedure in the study of structureproperty relations, especially in QSPR/QSAR study. In the latest couple of years, the amount of proposed nuclear descriptors is rapidly getting to be a result of the creation significance of these descriptors. They interface the particular physico-substance properties of mixture blends. A most seasoned, most considered and most prominent topological record among all degree based topological lists is Randic index, which was presented by Randic in 1975 [2]). This record was discovered reasonable with the end goal of medication plan [2], [3]. The numerical elements of Randic index incorporates its association with the standardized Laplacian framework [4], [5],[6],[9]. The formal definition of Randic index of a graph $\mathrm{G}$ is given as follows:

$$
R(G)=\sum_{u v \in E(G)} \frac{1}{\sqrt{d_{u} d_{v}}}
$$

Soon after the discovery of Randic index was introduced a general Randic index. It is denoted by $\mathrm{R}_{-}(\mathrm{G})$ and its formula is given as

$$
R_{\alpha}(G)=\sum_{u v \in E(G)}\left(d_{u} d_{v}\right)^{\alpha}
$$

where $\alpha$ is a non zero real number. Zhou et al. [7] introduced the general sum connectivity index $\chi_{\alpha}(\mathrm{G})$ and defined as

$$
\chi_{\alpha}(G)=\sum_{u v \in E(G)}\left(d_{u}+d_{v}\right)^{\alpha}
$$

where $\alpha$ is a real number. Shirdel et al. introduced a new degree based Zegreb index named as " hyper-Zegreb index " which is defined in [8], which is also known as general sumconnectivity index $\chi_{2}(\mathrm{G})$. The first general Zagreb index studies in [9].

$$
M_{\alpha}(G)=\sum_{u v \in E(G)}\left(d_{u}\right)^{\alpha}
$$

Estrada et al. invented atom-bond connectivity index which is abbreviated as $\mathrm{ABC}$ index [10]. $\mathrm{ABC}$ index is much importance due to its correlation with the thermodynamic properties of alkanes, see [11], [12]. The definition for $\mathrm{ABC}$ index is as follows

$$
A B C(G)=\sum_{u v \in E(G)} \sqrt{\frac{d_{u}+d_{v}-2}{d_{u} d_{v}}}
$$

The fourth version of $\mathrm{ABC}$ index was introduced by Ghorbani and Hosseinzadeh [13] and defined as 


$$
A B C_{4}(G)=\sum_{u v \in E(G)} \sqrt{\frac{S+S_{v}-2}{S_{u} S_{v}}}
$$

Recently the fifth version of GA is introduced by Graovac et al. [15] and defined as:

$$
G A_{5}(G)=\sum_{u v \in E(G)} \frac{2 \sqrt{S_{u} S_{v}}}{S_{u}+S_{v}}
$$

In [16], Ghorbani and Azimi defined first multiple Zagreb index $\mathrm{P}_{1}(\mathrm{G})$ and second multiple Zagreb index $\mathrm{PM}_{2}$ defined as:

$$
\begin{gathered}
P M_{1}(G)=\prod_{u v \in E(G)}\left(d_{u}+d_{v}\right), \\
P M_{2}(G)=\prod_{u v \in E(G)}\left(d_{u} d_{v}\right)
\end{gathered}
$$

These multiple Zagreb indices are studied for some chemical structures in [17], [18],[19],[20],[21] first Zagreb polynomial $\mathrm{M}_{1}(\mathrm{G} ; \mathrm{x})$ and second Zagreb polynomial $\mathrm{M}_{2}(\mathrm{G} ; \mathrm{x})$ are defined as:

$$
\begin{gathered}
M_{1}(G, x)=\prod_{u v \in E(G)} x\left(d_{u}+d_{v}\right), \\
M_{2}(G, x)=\prod_{u v \in E(G)} x\left(d_{u} d_{v}\right)
\end{gathered}
$$

The interested readers to be focused on the recent collection of topological indices [21], [22], [23],[24],[25],[26], [27].

\section{RESULTS AND DISCUSSION}

Keeffe et al. [28] have distributed around a quarter century a letter managing two 3D systemsof benzene one of the structure (Figure 1) was called 6.82P (additionally polybenzene) and has a place with the space gather $\operatorname{Im} 3 \mathrm{~m}$, comparing to the P-type surface. Actually this is inserting of the hexagon fix in the surface of negative ebb and flow P. The P-type surface is coordinated to the Cartesian arranges in the Euclidean space. More about this intermittent surface the peruser can discover in [29],[30]. This structure was required to be combined as $3 \mathrm{D}$ carbon solids: be that as it may, in our best learning, no such a combination was accounted for as such. This goal was to awaken the enthusiasm of researchers to the atomic acknowledgment of such pleasant thoughts in carbon nanoscience, as much as the graphenes were picked up a moment Nobel prize after C60, also the immediate union of fullerenes is currently a reality see detail in [31].

The graph $\mathrm{G}$ of benzene ring embedded in the P-typesurface network is shown in Figure 1

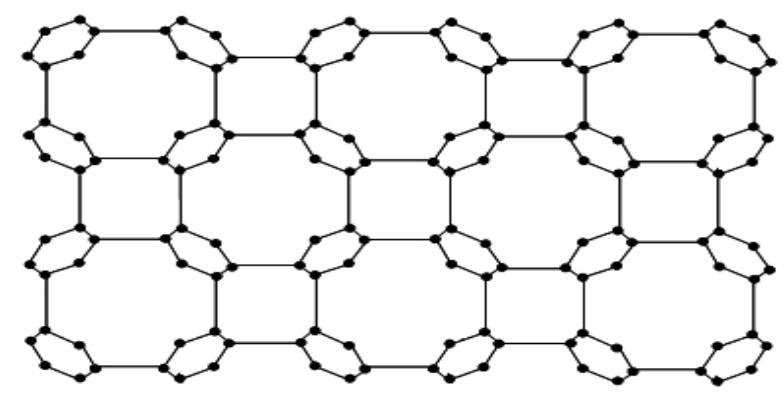

Figure 1: Benzene ring embedded in P-type surface in 2Dnetwork

A graph $G^{\prime}$ is called dual of a plane graph $G$ if the set of all faces of the graph $\mathrm{G}$ forms the vertex set of $G^{\prime}$. It is represented by $D_{u}(\mathrm{G})$. If an edge $\mathrm{e}$ is shared by faces $\mathrm{f}$ and $\mathrm{g}$ in planar graph $\mathrm{G}$ then $e^{\prime}$ joined respective vertices $f^{\prime}$ and $g^{\prime}$ in $D_{u}(\mathrm{G})$. Bounded dual is constructed if we delete the vertex which represents the unbounded face. It is not necessary that bounded dual of a simple plane graph is simple. If the bounded of simple plane graph is not simple then we remove the multiple edges in $\mathrm{B} d_{u}(\mathrm{G})$ to make it simple graph. We will denote the simple bounded dual of plane graph $\mathrm{G}$ by $\operatorname{Sb} d_{u}(\mathrm{G})$. The simple bounded dual of benzene ring embedded in P-type surface is shown in figure 2 and in more discrete form shown in figure 3

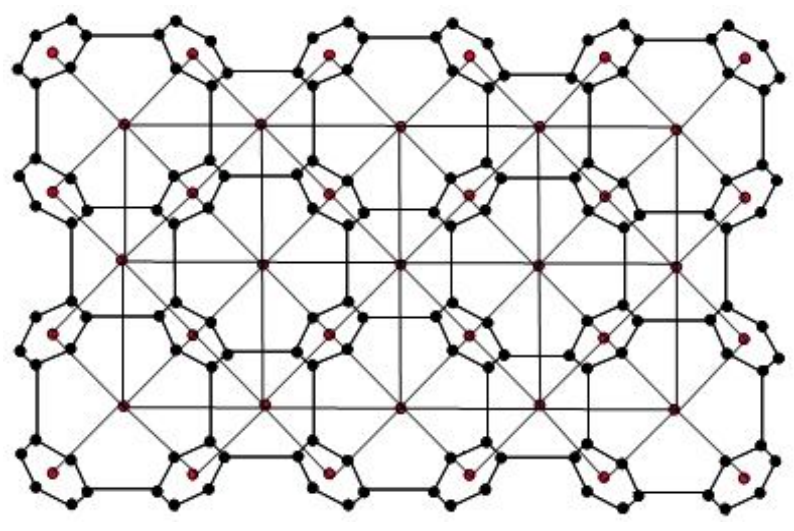

Figure 2: Construction of simple bounded dual of benzene ring embedded in P-type surface in 2D-network The number of total vertices in simple bounded dual of benzene ring embedded in Ptype

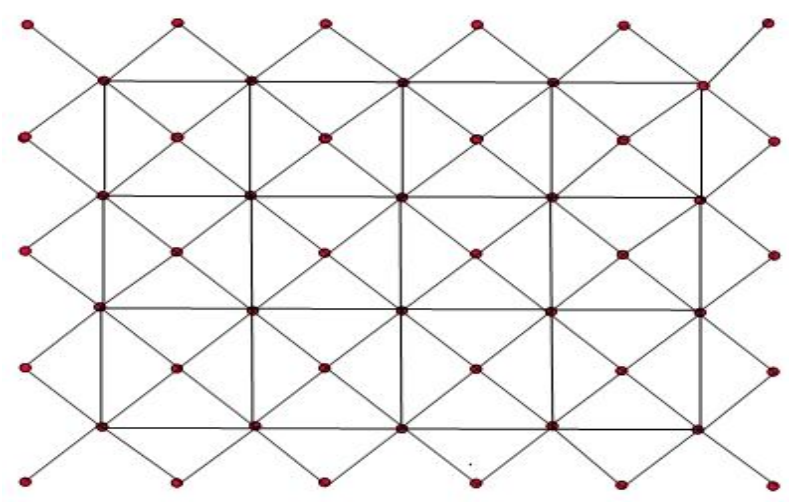

Figure 3: Simple bounded dual of benzene ring embedded in Ptype surface in 2D-network 
surface in $2 \mathrm{D}$ are $8 m n-2 m-2 n+1$, where $m$ is number of columns and $n$ number of rows of benzene ring embedded in P-type surface in 2D. Vertices of different degrees are presented in Table 1.

Let $\delta(\mathrm{G})$ and $\Delta(\mathrm{G})$ be the minimum and maximum degree of $\mathrm{G}$, respectively. The edge set $\mathrm{E}(\mathrm{G})$ can be divided into several partitions: for any $\mathrm{i}$ and $\mathrm{j}, \quad \delta(\mathrm{G}) \leq i, j \leq \Delta(G)$, let $E_{i, j}=\left\{e=u v \in E(G): d_{v}=i, d_{u}=j\right\}, e_{i, j}=\left|E_{i, j}\right|$ and $V_{i}=\left\{v \in V(G): d_{v}=i\right\}$

Table 1: The vertex partition of graph $\operatorname{Sb} d_{u}(\mathrm{G})$ based on degree of vertices, where $m, n \geq 2$.

\begin{tabular}{|c|c|}
\hline Degree of vertex & Number of vertices \\
\hline 1 & 4 \\
\hline 2 & $4 m+4 n-8$ \\
\hline 4 & $4 m n-4 m-4 n+4$ \\
\hline 6 & 4 \\
\hline 7 & $4 m+4 n-12$ \\
\hline 8 & $4 m n-6 m-6 n+9$ \\
\hline Total & $8 m n-2 n-2 n+1$ \\
\hline
\end{tabular}

Table 2: The edge partition of graph $\operatorname{Sbdu}(G)$ based on degree of end vertices of each edge, where $m, n \geq 2$

\begin{tabular}{|c|c|}
\hline $\begin{array}{c}\left(\mathrm{d}_{\mathrm{u}}, \mathrm{d}_{\mathrm{v}}\right), \text { where uv } \epsilon \\
\mathrm{E}\left(\mathrm{B} d_{u}(\mathrm{G})\right)\end{array}$ & Number of edges \\
\hline$(1,6)$ & 4 \\
\hline$(2,6)$ & 8 \\
\hline$(2,7)$ & $8 \mathrm{~m}+8 \mathrm{n}-24$ \\
\hline$(4,6)$ & 4 \\
\hline$(4,7)$ & $8 \mathrm{~m}+8 \mathrm{n}-24$ \\
\hline$(4,8)$ & $16 \mathrm{mn}-24 \mathrm{~m}-24 \mathrm{n}+36$ \\
\hline$(6,7)$ & 8 \\
\hline$(7,7)$ & $4 \mathrm{~m}+4 \mathrm{n}-16$ \\
\hline$(7,8)$ & $4 \mathrm{~m}+4 \mathrm{n}-12$ \\
\hline$(8,8)$ & $8 \mathrm{mn}-14 \mathrm{~m}-14 \mathrm{n}+24$ \\
\hline Total & $24 \mathrm{mn}-14 \mathrm{~m}-14 \mathrm{n}+8$ \\
\hline
\end{tabular}

\section{MAIN RESULTS}

Theorem 1. Let $\operatorname{Sb} d_{u}(\mathrm{G})$ be a simple bounded dual of $\mathrm{G}, \mathrm{G}$ be a benzene ring embedded in P-type-surface on 2D-network, then

$$
\begin{aligned}
M_{\alpha}\left(\operatorname{Sbd} d_{u}(\mathrm{G})\right) & =(4 \mathrm{~m}+4 \mathrm{n}-8) 2^{\alpha}+(4 \mathrm{mn}-4 \mathrm{~m}-4 \mathrm{n}+ \\
& 4) 4^{\alpha}+(4) 6^{\alpha}+(4 \mathrm{~m}+4 \mathrm{n}-12) 7^{\alpha}+ \\
& (4 \mathrm{mn}-6 \mathrm{~m}-6 \mathrm{n}+9) 8^{\alpha}+4, \\
R_{\alpha}\left(\operatorname{Sbd}_{u}(\mathrm{G})\right) \quad & =(4) 6^{\alpha}+(8) 12^{\alpha}+(8 \mathrm{~m}+8 \mathrm{n}-24) 14^{\alpha}+ \\
& (4) 24^{\alpha}+(8 \mathrm{~m}+8 \mathrm{n}-24) 28^{\alpha} \\
& +(16 \mathrm{mn}-24 \mathrm{~m}-24 \mathrm{n}+36) 2^{5 \alpha}+(8) 42^{\alpha} \\
& +(4 \mathrm{~m}+4 \mathrm{n}-16) 7^{2 \alpha} \\
& +(4 \mathrm{~m}+4 \mathrm{n}-12) 56^{\alpha}+(8 \mathrm{mn}-14 \mathrm{~m}-14 \mathrm{n}+ \\
& 24) 2^{6 \alpha}, \\
& =(4) 7^{\alpha}+(8) 2^{3 \alpha}+(8 \mathrm{~m}+8 \mathrm{n}-24) 3^{2 \alpha}+ \\
& (4) 10^{\alpha}+(8 \mathrm{~m}+8 \mathrm{n}-24) 11^{\alpha} \\
& +(16 \mathrm{mn}-24 \mathrm{~m}-24 \mathrm{n}+36) 12^{\alpha}+(8) 13^{\alpha} \\
& +(4 \mathrm{~m}+4 \mathrm{n}-16) 14^{\alpha} \\
& +(4 \mathrm{~m}+4 \mathrm{n}-12) 15^{\alpha}+(8 \mathrm{mn}-14 \mathrm{~m}-14 \mathrm{n}+
\end{aligned}
$$

$$
\text { 24) } 2^{4 \alpha}
$$

where $\alpha$ is a real number.

Proof. The number of vertices in $\mathrm{Sb} d_{u}(\mathrm{G})$ are given in Table 1 . Since the formula for $M_{-}(G)$ is given

$$
\begin{aligned}
& \quad M_{\alpha}(G)=\sum_{u \in V(G)}\left(d_{u}\right)^{\alpha} \\
& M_{\alpha}(G)=V_{1}(1)^{\alpha}+V_{2}(2)^{\alpha}+V_{4}(4)^{\alpha}+V_{6}(6)^{\alpha}+V_{7}(7)^{\alpha}+ \\
& V_{8}(8)^{\alpha},
\end{aligned}
$$

where $V_{i}$ represents the cardinality of vertex of degree $i$.

$M_{\alpha}\left(\operatorname{Sbd}_{u}(G)\right)=4+(4 \mathrm{~m}+4 \mathrm{n}-8) 2^{\alpha}+(4 \mathrm{mn}-4 \mathrm{~m}-4 \mathrm{n}+4) 4^{\alpha}+$ $(4) 6^{-}+(4 m+4 n-12) 7^{\alpha}-+(4 m n-6 m-6 n+9) 8^{\alpha}$ :

The number of edges in $\operatorname{Sbdu}(\mathrm{G})$ are $24 m n-14 m-14 n+8$. The edge partition based on the degree of the end vertices of each edge are shown in Table 2. Since, the formula of general Randic index is this implies that and the formula of general sumconnectivity is

$$
\begin{aligned}
& R_{\alpha}(G)=\sum_{u v \in E(G)}\left(d_{u} d_{v}\right)^{\alpha} \\
& R_{\alpha}(\operatorname{Sbdu}(\mathrm{G}))=\mathrm{e}_{1,6}(1 * 6)^{\alpha}+\mathrm{e}_{2,6}(2 * 6)^{\alpha}+\mathrm{e}_{2,7}(2 * 7)^{\alpha} \\
& +\mathrm{e}_{4,6}(4 * 6)^{\alpha}+\mathrm{e}_{4,7}(4 * 7)^{\alpha}+\mathrm{e}_{4,8}(4 * 8)^{\alpha} \\
& +\mathrm{e}_{6,7}(6 * 7)^{\alpha}+\mathrm{e}_{7,7}(7 * 7)^{\alpha}+\mathrm{e}_{7,8}(7 * 8)^{\alpha} \\
& +\mathrm{e}_{8,8}(8 * 8)^{\alpha},=(4) 6^{\alpha}+(8) 12^{\alpha}+(8 \mathrm{~m}+ \\
& 8 \mathrm{n}-24) 14^{\alpha}+(4) 24^{\alpha}+(8 \mathrm{~m}+8 \mathrm{n}-24) 28^{\alpha}+ \\
& (16 m n-24 n-24 n+36) 2^{5 \alpha}+(8) 42^{\alpha}+(4 m \\
& +4 \mathrm{n}-16) 7^{2 \alpha}+(4 \mathrm{~m}+4 \mathrm{n}-12) 56^{\alpha}+(8 \mathrm{mn}- \\
& 14 m-14 n+24) 2^{6 \alpha} \text {, } \\
& \chi_{\alpha}(G)=\sum_{u v \in E(G)}\left(d_{u}+d_{v}\right)^{\alpha} \\
& \chi_{\alpha}(\operatorname{Sbdu}(\mathrm{G}))=\mathrm{e}_{1,6}(1+6)^{\alpha}+\mathrm{e}_{2,6}(2+6)^{\alpha}+\mathrm{e}_{2,7}(2+ \\
& 7)^{\alpha}+\mathrm{e}_{4,6}(4+6)^{\alpha}+\mathrm{e}_{4,7}(4+7)^{\alpha}+ \\
& \mathrm{e}_{4,8}(4+8)^{\alpha}+\mathrm{e}_{6,7}(6+7)^{\alpha}+\mathrm{e}_{7,7}(7+ \\
& 7)^{\alpha}+\mathrm{e}_{7,8}(7+8)^{\alpha}+\mathrm{e}_{8,8}(8+8)^{\alpha},=(4) 7^{\alpha} \\
& +(8) 2^{3 \alpha}+(8 \mathrm{~m}+8 \mathrm{n}-24) 3^{2 \alpha}+(4) 10^{\alpha}+ \\
& (8 \mathrm{~m}+8 \mathrm{n}-24) 11^{\alpha}+(16 \mathrm{mn}-24 \mathrm{n}-24 \mathrm{n}+ \\
& \text { 36) } 12^{\alpha}+(8) 13^{\alpha}+(4 \mathrm{~m}+4 \mathrm{n}-16) 14^{\alpha}+ \\
& (4 \mathrm{~m}+4 \mathrm{n}-12) 15^{\alpha}+(8 \mathrm{mn}-14 \mathrm{~m}-14 \mathrm{n}) 2^{4 \alpha}
\end{aligned}
$$

This completes the proof.

Theorem 2. The atom-bond connectivity index ABC of simple bounded dual of the benzene ring embedded in the P-type-surface network is given by

$$
\begin{aligned}
& \mathrm{ABC}\left(\operatorname{Sbd}_{u}(G)\right)=(4 \sqrt{5}+\sqrt{14}) m n+(4 \sqrt{2}-6 \sqrt{5}+ \\
& (12 \sqrt{7}+\sqrt{182}+8 \sqrt{3}) / 7(m+n)+(-8 \sqrt{2}+9 \sqrt{5}+ \\
& 3 \sqrt{14}+(2 \sqrt{30}+4 \sqrt{3}) / 3-(36 \sqrt{7}-32 \sqrt{3}+ \\
& 3 \sqrt{182}) / 7+4 \sqrt{462} / 21
\end{aligned}
$$

Proof. The number of edges are mentioned in Table. 2.,

By using Table. 2, after simplification we get 
$\operatorname{ABC}\left(\operatorname{Sbd}_{u}(G)\right)=(4 \sqrt{5}+\sqrt{14}) m n+(4 \sqrt{2}-6 \sqrt{5}+$

$(12 \sqrt{7}+\sqrt{182}+8 \sqrt{3}) / 7(m+n)+(-8 \sqrt{2}+9 \sqrt{5}+$

$3 \sqrt{14}+(2 \sqrt{30}+4 \sqrt{3}) / 3-(36 \sqrt{7}-32 \sqrt{3}+$

$3 \sqrt{182)} / 7+4 \sqrt{462 / 21}$

This completes the proof.

Theorem 3. The geometric-arithmetic index GA of simple bounded dual of benzene ring embedded in the P-type-surface network is given by

$$
\begin{aligned}
& G A\left(\operatorname{Sbdu}(G)=((32 \sqrt{3}+8) / 3) m n+\left(\frac{128 \sqrt{14}}{45}-\right.\right. \\
& \left.\frac{32 \sqrt{7}}{11}-16 \sqrt{2}-10\right)(m+n)+(4 \sqrt{13}+24 \sqrt{2}+8- \\
& \frac{96 \sqrt{7}}{11}+\frac{16 \sqrt{42}}{13}+96 \frac{\sqrt{6}}{35}-128 \frac{\sqrt{14}}{15}
\end{aligned}
$$

Proof. The number of edges are mentioned in Table 2. Since, the geometric-arithmetic index is defined as after simplifications we get

$$
G A(G)=\sum_{u v \in E(G)} \frac{2 \sqrt{d_{u} d_{v}}}{d_{u}+d_{v}}
$$

By using Table. 2, after simplification we get

$$
\begin{aligned}
& G A\left(\operatorname{Sbdu}(G)=\left(\frac{32 \sqrt{3}+8}{3}\right) m n+\left(\frac{128 \sqrt{14}}{45}-\frac{32 \sqrt{7}}{11}-\right.\right. \\
& 16 \sqrt{2}-10)(m+n)+\left(4 \sqrt{13}+24 \sqrt{2}+8-\frac{96 \sqrt{7}}{11}+\right. \\
& \frac{16 \sqrt{42}}{13}+96 \frac{\sqrt{6}}{35}-128 \frac{\sqrt{14}}{15}
\end{aligned}
$$

In the next two theorems we calculated the fourth atombond connectivity index $\mathrm{ABC}_{4}$ and the fifth geometricarithmetic index $\mathrm{GA}_{5}$. There are twenty four types of edges on degree based sum of neighbors vertices of each edge in the simple bounded dual of benzene ring embedded in the P-typesurface network.

Table 3: The edge partition of graph $\operatorname{Sbdu}(\mathrm{G})$ based on degree sum of neighbor vertices of end vertices of each edge. where $m ; n$ $\geq 3$.

\begin{tabular}{|c|c|}
\hline$\left(\mathrm{S}_{\mathrm{u}}, \mathrm{Sv}\right) ; \begin{array}{c}\text { where uv } \geq 2 \mathrm{E} \text { (Sbdu } \\
(\mathrm{G}))\end{array}$ & Number of edges \\
\hline$(6,23)$ & 4 \\
\hline$(13,23)$ & 8 \\
\hline$(13,33)$ & 8 \\
\hline$(14,33)$ & 8 \\
\hline$(14,34)$ & $8 \mathrm{~m}+8 \mathrm{n}-40$ \\
\hline$(23,28)$ & 4 \\
\hline$(23,33)$ & 8 \\
\hline$(28,33)$ & 8 \\
\hline$(28,46)$ & 4 \\
\hline$(30,33)$ & 8 \\
\hline$(30,34)$ & $8 \mathrm{~m}+8 \mathrm{n}-40$ \\
\hline$(30,46)$ & 8 \\
\hline$(30,47)$ & $8 \mathrm{~m}+8 \mathrm{n}-40$ \\
\hline$(32,46)$ & 4 \\
\hline$(32,47)$ & $8 \mathrm{~m}+8 \mathrm{n}-40$ \\
\hline
\end{tabular}

\begin{tabular}{|c|c|}
\hline$(32,48)$ & $16 \mathrm{mn}-40 \mathrm{~m}-40 \mathrm{n}+100$ \\
\hline$(33,34)$ & 8 \\
\hline$(33,46)$ & 8 \\
\hline$(34,34)$ & $4 \mathrm{~m}+4 \mathrm{n}-24$ \\
\hline$(34,47)$ & $4 \mathrm{~m}+4 \mathrm{n}-20$ \\
\hline$(46,47)$ & 8 \\
\hline$(47,47)$ & $4 \mathrm{~m}+4 \mathrm{n}-24$ \\
\hline$(47,48)$ & $4 \mathrm{~m}+4 \mathrm{n}-20$ \\
\hline$(48,48)$ & $8 \mathrm{mn}-22 \mathrm{~m}-22 \mathrm{n}+60$ \\
\hline Total & $24 \mathrm{mn}-14 \mathrm{~m}-14 \mathrm{n}+8$ \\
\hline
\end{tabular}

Theorem 4. Let $\mathrm{G}$ be a benzene ring embedded in the P-typesurface network, then

$$
\begin{aligned}
\text { 1. } \mathrm{HM}(\operatorname{Sbdu}(\mathrm{G}))= & 4352 \mathrm{mn}-3740(\mathrm{~m}+\mathrm{n})+3104 \\
\text { 2. } \mathrm{PM}_{1}(\operatorname{Sbdu}(\mathrm{G}))=\quad & 2^{(64 \mathrm{mn}-100 \mathrm{~m}-100 \mathrm{n}+180) *} 3^{(16 \mathrm{mn}-4 \mathrm{~m}-4 \mathrm{n}-} \\
& 24) * 5^{(4 \mathrm{~m}+4 \mathrm{n}-8)} * 7^{(4 \mathrm{~m}+4 \mathrm{n}-12)} * 11^{(8 \mathrm{~m}+8 \mathrm{n}-} \\
& 24) * 13^{(8)} \\
& 2^{(128 \mathrm{mn}-168 \mathrm{~m}-168 \mathrm{n}+256)} * 3^{(24)} * 7^{(28 \mathrm{~m}+28 \mathrm{n}} \\
\mathrm{PM}_{2}(\operatorname{Sbdu}(\mathrm{G}))= & (4) \mathrm{x}^{7}+(8) \mathrm{x}^{8}+(8 \mathrm{~m}+8 \mathrm{n}-24) \mathrm{x}^{9}+ \\
\mathrm{M} 1(\operatorname{Sbdu}(\mathrm{G}), \mathrm{x})= & (4) \mathrm{x}^{10}+(8 \mathrm{~m}+8 \mathrm{n}-24) \mathrm{x}^{11}+(16 \mathrm{mn}- \\
& 24 \mathrm{~m}-24 \mathrm{n}+36) \mathrm{x}^{12}+(8) \mathrm{x}^{13}+(4 \mathrm{~m}+ \\
& 4 \mathrm{n}-16) \mathrm{x}^{14}+(4 \mathrm{~m}+4 \mathrm{n}-12) \mathrm{x}^{15}+ \\
& (8 \mathrm{mn}-14 \mathrm{~m}-14 \mathrm{n}+24) \mathrm{x}^{16} \\
& =(4) \mathrm{x}^{6}+(8) \mathrm{x}^{12}+(8 \mathrm{~m}+8 \mathrm{n}-24) \mathrm{x}^{14} \\
& +(4) \mathrm{x}^{24}+(8 \mathrm{~m}+8 \mathrm{n}-24) \mathrm{x}^{28}+ \\
& (16 \mathrm{mn}-24 \mathrm{n}-24 \mathrm{n}+36) \mathrm{x}^{32}+(8) \mathrm{x}^{42}+ \\
\mathrm{M} 2(\operatorname{Sbdu}(\mathrm{G}), \mathrm{x})=(4 \mathrm{~m}+4 \mathrm{n}-16) \mathrm{x}^{49}+(4 \mathrm{~m}+4 \mathrm{n}-12) \mathrm{x}^{56} & +(8 \mathrm{mn}-14 \mathrm{~m}-14 \mathrm{n}+24) \mathrm{x}^{64}
\end{aligned}
$$

Proof. Let $\mathrm{G}$ be a benzene ring embedded in the P-typesurface network. The edge set $\mathrm{E}(\operatorname{Sbdu}(\mathrm{G}))$ divided into ten edge partitions based on degree of end vertices. The number of edges of edges partitions are given in Table 1 . By using Table 1 and Table 3, after simplification we get,

$\mathrm{HM}(\operatorname{Sbdu}(\mathrm{G}))=4352 \mathrm{mn}-3740(\mathrm{~m}+\mathrm{n})+3104$, Since,

$$
P M_{1}(G)=\prod_{u v \in E(G)}\left(d_{u}+d_{v}\right)
$$

After simplification we get

$$
\begin{aligned}
\mathrm{PM}_{1}(\operatorname{Sbdu}(\mathrm{G}))= & \left.2^{(64 \mathrm{mn}-100 \mathrm{~m}} \quad-100 \mathrm{n}+180\right) * 3^{(16 \mathrm{mn}-4 \mathrm{~m}-4 \mathrm{n}-} \\
& 24) * 5^{(4 \mathrm{~m}+4 \mathrm{n}-8)} * 7^{(4 \mathrm{~m}+4 \mathrm{n}-12)} * 11^{(8 \mathrm{~m}+8 \mathrm{n}-24)} \\
& * 13^{(8)}
\end{aligned}
$$

We know that

$$
P M_{2}(G)=\prod_{u v \in E(G)}\left(d_{u} d_{v}\right)
$$


so using this and simplification we get $\mathrm{PM}_{2}(\operatorname{Sbdu}(\mathrm{G}))=2^{(128 \mathrm{mn}-168 \mathrm{~m}-168 \mathrm{n}+256)} * 3^{(24)} * 7^{(28 \mathrm{~m}+28 \mathrm{n}-84)}$.

Similarly

$\begin{aligned} \operatorname{M1}(\operatorname{Sbdu}(G), x) & =(4) x^{7}+(8) x^{8}+(8 m+8 n-24) x^{9}+ \\ & (4) x^{10}+(8 m+8 n-24) x^{11}+(16 m n- \\ & 24 m-24 n+36) x^{12}+(8) x^{13}+(4 m+4 n- \\ & 16) x^{14}+(4 m+4 n-12) x^{15}+(8 m n- \\ & 14 m-14 n+24) x^{16}\end{aligned}$

and

$\begin{aligned} M 2(\operatorname{Sbdu}(G), x) & =(4) x^{6}+(8) x^{12}+(8 m+8 n-24) x^{14} \\ & +(4) x^{24}+(8 m+8 n-24) x^{28}+(16 m n- \\ & 24 n-24 n+36) x^{32}+(8) x^{42}+(4 m+4 n- \\ & 16) x^{49}+(4 m+4 n-12) x^{56}+(8 m n- \\ & 14 m-14 n+24) x^{64}\end{aligned}$

Hence proved.

\section{CLOSING REMARKS}

In this paper, we deal with simple bounded dual of benzene ring embedded in the P-type-surface network and studies their topological indices. We determined first general Zagreb index $\mathrm{M}$, general Randic connectivity index $\mathrm{R}_{-}$, general sum-connectivity index $\chi_{\alpha}$, atom-bond connectivity index $\mathrm{ABC}$, geometric-arithmetic index $\mathrm{GA}$, fourth atom bound connectivity index $\mathrm{ABC}_{4}$, fifth geometric-arithmetic index $\mathrm{GA}_{5}$, hyper-Zagreb index $\mathrm{HM}(\operatorname{Sbdu}(\mathrm{G}))$; first multiple Zagreb index $\mathrm{PM}_{1}(\operatorname{Sbdu}(\mathrm{G}))$, second multiple Zagreb index $\mathrm{PM}_{2}(\operatorname{Sbdu}(\mathrm{G}))$ and Zagreb polynomials $\mathrm{M}_{1}(\operatorname{Sbdu}(\mathrm{G}) ; \mathrm{x})$, $\mathrm{M}_{2}(\operatorname{Sbdu}(\mathrm{G}) ; \mathrm{x})$.

\section{REFERENCES}

1. K. H. Rosen and K. Krithivasan, Discrete Mathematics and Its Applications: With Com- Binatorics and Graph Theory. Tata McGraw-Hill Education, 2012.

2. M. Randic, Characterization of Molecular Branching, Journal of the American ChemicalSociety, vol. 97, no. 23, pp. 6609-6615, 1975.

3. I. Gutman, B. Ruic, N. Trinajstic, and C. F. Wilcox Jr, Graph Theory and Molecular Orbitals. Xii. Acyclic Polyenes, The Journal of Chemical Physics, vol. 62, no. 9, pp.3399-3405, 1975.

4. S.B.Bozkurt, A.D. Gungor, I. Gutman, and A.S. Cevik, Randic Matrix and Randic Energy, MATCH Commun. Math. Comput. Chem, vol. 64, pp. 239-250, 2010.

5. M. Cavers, S. Fallat, and S. Kirkland, On the Normalized Laplacian Energy and General Randic Index R-1 of Graphs, Linear Algebra and its Applications, vol. 433, no. 1, pp.172-190, 2010.

6. I. Gutman, B. Furtula, and S. B. Bozkurt, On Randic Energy, Linear Algebra and itsApplications, vol. 442, pp. 50-57, 2014.
7. B. Zhou and N. Trinajstic, On General Sum-Connectivity Index, Journal of mathematicalchemistry, vol. 47, no. 1, pp. 210-218, 2010.

8. G. Shirdel, H. Rezapour, and A. Sayadi, The HyperZagreb Index of Graph Operations, Iranian Journal of Mathematical Chemistry, vol. 4, no. 2, pp. 213-220, 2013.

9. X. Li and H. Zhao, Trees With the First Three Smallest and Largest Generalized Topological Indices, MATCH Commun. Math. Comput. Chem, vol. 50, pp. 57-62, 2004.

10. E. Estrada, L. Torres, L. Rodriguez, and I. Gutman, An Atom-Bond Connectivity Index:Modelling the Enthalpy of Formation of Alkanes, 1998.

11. E. Estrada, Atom-Bond Connectivity and The Energetic of Branched Alkanes, Chemical Physics Letters, vol. 463, no. 4\{6, pp. 422-425, 2008.

12. I. Gutman, J. Tosovic, S. Radenkovic, and S. Markovic, On Atom-Bond Connectivity Index and Its Chemical Applicability, 2012.

13. M. Ghorbani and M. Hosseinzadeh, Computing ABC4 Index of Nano Star Dendrimers, Optoelectron. Adv. Mater. Rapid Commun, vol. 4, pp. 1419-1422, 2010.

14. D. Vukicevic and B. Furtula, Topological Index Based On the Ratios of Geometrical and Arithmetical Means of End-Vertex Degrees of Edges, Journal of mathematical chemistry, vol. 46, no. 4, pp. 1369-1376, 2009.

15. Z. Du, B. Zhou, and N. Trinajstic, On GeometricArithmetic Indices of (Molecular) Trees, Unicyclic Graphs and Bicyclic Graphs, MATCH Commun. Math. Comput. Chem, vol. 66, pp. 681-697, 2011.

16. M.Ghorbani and N.Azimi , Note On Multiple Zagreb Indices, Iranian Journal of Mathematical Chemistry, vol. 3, no. 2, pp. 137-143, 2012.

17. B. Borovicanin, On the Extremal Zagreb Indices of Trees With Given Number of Segments or Given Number of Branching Vertices, MATCH Commun. Math. Comput. Chem, vol. 74, no. 1, pp. 57-79, 2015.

18. M. Eliasi, A. Iranmanesh, and I. Gutman, Multiplicative Versions of First Zagreb Index, Match-Communications in Mathematical and Computer Chemistry, vol. 68, no. 1, p. 217,2012 .

19. I. Gutman, B. Furtula, Z. K. Vukicevic, and G. Popivoda, On Zagreb Indices and Coindices, MATCH Commun. Math. Comput. Chem, vol. 74, no. 1, pp. 5-16, 2015.

20. X. Li and Y. Shi, A Survey On the Randic Index, MATCH Commun. Math. Comput. Chem, vol. 59, no. 1, pp. 127-156, 2008.

21. Y. Shi, Note On Two Generalizations of The Randic Index, Applied Mathematics and Computation, vol. 265, pp. 1019-1025, 2015.

22. M. Baca, J. Horvathova, M. Mokrisova, and A. Suhanyiova, On Topological Indices of Fullerenes, Applied Mathematics and Computation, vol. 251, pp. 154$161,2015$. 
23. H. Sector, Computing Topological Polynomials of Certain Nanostructures, Journal of Ptoelectronics and Advanced Materials, vol. 17, no. 5, pp. 877-883,2015.

24. A. A. Dobrynin, R. Entringer, and I. Gutman, Wiener Index of Trees: Theory and Applications, Acta Applicandae Mathematica, vol. 66, no. 3, pp. 211-249, 2001.

25. S. Hayat and M. Imran, On Degree Based Topological Indices of Certain Nanotubes, Journal of Computational and Theoretical Nanoscience, vol. 12, no. 8, pp. 1599$1605,2015$.

26. S. Hayat and M. Imran, Computation of Topological Indices of Certain Networks, Applied Mathematics and Computation, vol. 240, pp. 213-228, 2014.

27. S. Hayat and M. Imran, Computation of Certain Topological Indices of Nanotubes Covered By C5 And C7, Journal of Computational and Theoretical Nanoscience, vol. 12, no. 4, pp. 533-541, 2015.

28. M. OaoAZKee_e, G. B. Adams, and O. F. Sankey, Predicted New Low Energy Forms of Carbon, Physical review letters, vol. 68, no. 15, pp. 23-25, 1992.

29. M. V. Diudea, Nanostructures: Novel Architecture. Nova Publishers, 2005

30. M. V. Diudea and C. L. Nagy, Periodic Nanostructures. Springer Science and Business Media, vol. 7, 2007.

31. A. Ahmad, On the Degree Based Topological Indices of Benzene Ring Embedded In P-Type-Surface In 2D Network, Hacet. J. Math. Stat, vol. 47, pp. 9-18, 2018. 